INDO GLOBAL JOURNAL OF

PHARMACEUTICAL SCIENCES

ISSN 2249- 1023

\title{
A Study on the Phytochemical Properties and Antioxidant Activity of Moringa oleifera (PKM-1) Seed Extract
}

\author{
Devanshu Agnihotri ${ }^{1 *}$, Prateek Tripathi ${ }^{2}$, Aprajita Tripathi ${ }^{3}$, Richa Pandey ${ }^{4}$, Manoj Rawat ${ }^{5}$ \\ ${ }^{1}$ Institute of Biosciences \& Biotechnology, CSJM University, Kanpur -208024, India \\ ${ }^{2}$ School of Biotechnology, KIIT University, Bhubneswar- 751024, India \\ ${ }^{3}$ Gautam Budhha University, Greater Noida - 201312, India \\ ${ }^{4}$ Shriramswaroop Memorial University, Deva Road, Lucknow -225003, India \\ ${ }^{5}$ Biotech Park, Sector G, Jankipuram, Kursi Road, Lucknow, Uttar Pradesh 226021, India
}

Address for Correspondance: Devanshu Agnihotri, devanshuagnihotri@yahoo.com ; Prateek Tripathi, prateektripathi94@gmail.com ; Aprajita Tripathi, aprajitatripathi21@gmail.com; Richa Pandey, richapandey1223@gmail.com

Keywords Moringa oleifera; Seed

Extract; Anti-

Oxidant; Metals.
ABSTRACT: A laboratory incubation experiment was conducted to evaluate phytochemical properties of common edible seed species, Moringa oleifera (PKM-1), representing family Moringaceae. Extraction was done in a specially designed apparatus called Soxhlet apparatus. The oil obtained was then analyzed through different analytical techniques. Distinct susceptibility characteristics were observed when seed and pod extract were analysed respectively, for phytochemicals. Alkaloids and proteins were found in the seed extracts while tannins and flavonoids were qualitatively analyzed in leaf extract. Metal ions like iron, copper, lead, sodium and potassium were present in the range between $0.017-10 \mathrm{ppm}$. In addition, potential anti-oxidant activity was also determined, which turned out to be significant in the range of $25-100 \mu \mathrm{g} / \mathrm{ml}$ (pod less) and $100-$ $500 \mu \mathrm{g} / \mathrm{ml}$ (with pod), with maximum activity at 100 and $500 \mu \mathrm{g} / \mathrm{ml}$. Future work will entail understanding the use of seed extract as an antioxidant as well as for skin applications. (C) 2016 iGlobal Research and Publishing Foundation. All rights reserved.

Conference Proceedings: International Conference on Advances in Plant and Microbial Biotechnology (PMB2017); JIIT, Noida: February 02-04, 2017

Indo Global Journal of Pharmaceutical Sciences( ISSN 22491023 ; CODEN- IGJPAI; NLM ID: 101610675) indexed and abstracted in EMBASE(Elsevier), SCIRUS(Elsevier),CABI, CAB Abstracts, Chemical Abstract Services(CAS), American Chemical Society(ACS), Index Copernicus, EBSCO, DOAJ, Google Scholar and many more. For further details, visit http://iglobaljournal.com 